\title{
Measures of health-related quality of life in PCOS women: a systematic review
}

This article was published in the following Dove Press journal:

International Journal of Women's Health

\section{Zahra Behboodi \\ Moghadam' \\ Bita Fereidooni² \\ Mohsen Saffari ${ }^{3}$ \\ Ali Montazeri ${ }^{4}$}

'Department of Reproductive Health, School of Nursing and Midwifery,

Tehran University of Medical Sciences, Tehran, Iran; ${ }^{2}$ Department of Reproductive Health, School of Nursing and Midwifery, Tehran University of Medical Sciences, Tehran, Iran; ${ }^{3}$ Health Research Center, Life Style Institute, Baqiyatallah University of Medical Sciences, Tehran, Iran; ${ }^{4}$ Population Health Research Group, Health Metrics Research Center, Iranian Institute for Health Sciences Research, ACECR, Tehran, Iran
Correspondence: Bita Fereidooni Department of Reproductive Health, School of Nursing and Midwifery, Tehran University of Medical Sciences, Tohid Square, East Nosrat St, Tehran, Iran Email barshimah@yahoo.com

\section{Ali Montazeri}

Population Health Research Group, Health Metrics Research Center, Iranian Institute for Health Sciences Research, Academic Center for Education, Culture and Research, Tehran, Iran Email montazeri@acecr.ac.ir
Introduction: Polycystic ovary syndrome (PCOS) is associated with biochemical and hormonal disturbance and adverse cosmetic, reproductive, metabolic, and psychological consequences, resulting in reduced health-related quality of life (HRQoL). Various generic and specific questionnaires have been used for assessing different dimensions of HRQoL in PCOS women. The purpose of this systematic review was to identify those general and specific instruments and to determine the factors that affect HRQoL in PCOS women.

Materials and methods: The research strategy involved general and specific terms in relation to PCOS women and their QoL. A review was performed on studies that were published between 1945 to 2017 and that were indexed in MEDLINE, ISI Web of Science, and Scopus. A narrative synthesis of the data was provided.

Results: In total, 52 studies ( 9 qualitative and 43 quantitative) were included in the review. The analysis indicated that 3 specific and 5 general instruments were used to measure the QoL in PCOS women. Of these, the 36-Item Short Form Health Survey (SF-36) and the Polycystic Ovary Syndrome Health-Related Quality of Life Questionnaire (PCOSQ) were used most frequently. All studies assessed different aspects of QoL in PCOS women and found that PCOS had negative effects on QoL in this population.

Conclusion: The PCOSQ and the SF-36 were used most frequently for the assessment of QoL in PCOS women. Perhaps using either a specific questionnaire solely or a specific questionnaire in conjunction with a generic measure would be more appropriate when measuring QoL in PCOS women. However, both questionnaires showed that they are able to capture different aspects of QoL in PCOS women and to identify areas that can help to improve QoL in these women.

Keywords: polycystic ovary syndrome, health-related quality of life, questionnaires, systematic review

\section{Introduction}

Polycystic ovary syndrome (PCOS) is the most common hormonal disturbance that, depending on the population studied and diagnostic criteria, affects up to $15 \%-20 \%$ of women at reproductive age. ${ }^{1,2}$ The pathophysiology of this heterogeneous disease has not been clearly determined, but it is believed that it results from complex interactions between genetic, metabolic, and environmental factors. ${ }^{3}$ It is characterized by hyperandrogenism, ovulatory dysfunction, and polycystic ovarian morphology. ${ }^{4} \mathrm{PCOS}$ is associated with adverse clinical complications including reproductive (menstrual irregularity and infertility), ${ }^{2,3}$ metabolic (insulin resistance, diabetes, and cardiovascular risk), ${ }^{5}$ and psychological disabilities (anxiety and depression). ${ }^{6}$ All have been mentioned as factors responsible for the reduction of life quality. ${ }^{7}$

Health-related quality of life (HRQoL) is a multidimensional concept used to describe physical, emotional, and social aspects of particular diseases or their treatment. ${ }^{8}$ 
Chronic disorders such as PCOS may have major effects on the QoL that need to be precisely assessed. ${ }^{9}$

HRQoL can be assessed using both general and specific tools. General tools have generally no questions for specific conditions and diseases. ${ }^{10}$ Therefore, specific tools are generally preferable for each condition assessed, and PCOS is no exception. However, both tool types have been used for measuring QoL in the literature. The aims of this study were to identify 1) studies that have used standard instruments to measure HRQoL in women with PCOS; 2) general and specific instruments that have been used for assessing HRQoL in PCOS women; and 3) the effects of PCOS on different aspects of women's QoL.

\section{Methods}

\section{Search engines}

The electronic databases searched included MEDLINE (January 1950-March 2017), ISI Web of Knowledge (January 1945-26 July 2017), Scopus (May 2000-January 2017), and Google Scholar (March 1996-January 2017). More data were collected from the reference lists and databases related to scientific conference, and we contacted the authors of the publications to know they had any other studies which had remained unpublished.

\section{Search strategy}

In the current systematic review article, we managed to find general and specific instruments that assessed QoL, and we further delineated the factors relevant to QoL in women suffering from PCOS using key words: (questionnaire OR scale OR inventory) AND ("Quality of life" OR "Health-related quality of life" OR "Patient-Reported Outcome") AND ("Polycystic ovary syndrome" OR "PCOS").

\section{Inclusion criteria}

The following criteria were used to decide which relevant resources to be included:

1. Document type: article;

2. Article type: original, review, and theoretical;

3. Language: English;

4. Study design: qualitative, quantitative, and mixed methods;

5. Species: humans;

6. Subject: health and medicine;

7. Documents' subjects: QoL and its related factors in PCOS women; and

8. Questionnaire used for HRQoL: measured more than one dimension.

\section{Data synthesis}

Two authors were asked to go through the title and abstract of the studies obtained and to read the full texts finally to decide which studies had met the criteria to be included in the current systematic review. The variables of interest were the first author's name, year, country, study design, and study results. The two authors negotiated any disagreements to reach consensus.

In order to assess HRQoL measures, the Consensus-based Standards for the Selection of Health Status Measurement Instruments checklist was employed. Specifically, we assessed measures for the following criteria: internal consistency, reliability, content validity, construct validity, and factor analysis. ${ }^{11}$

\section{Results}

\section{Statistics}

In all, 4,269 citations were identified. After removing duplicates $(n=486)$, the remaining 3,783 citations were assessed, and an additional 3,161 irrelevant records were excluded. Of the remaining 622 papers, 570 articles were also removed because they were not eligible, and finally 52 full-text articles were included in the analysis (Figure 1). Of these, 9 studies were qualitative and had focused upon the impact of PCOS on patients' HRQoL. ${ }^{12-20}$ The remaining 43 studies were quantitative which are summarized in Table 1. The frequency of studies on QoL in PCOS women from various countries $(n=52)$ was as follows: USA $(n=13), \operatorname{UK}(n=9)$, Iran $(n=7)$, Australia ( $n=3)$, Germany ( $n=5)$, Sweden $(n=2)$, Italy $(n=2)$, Canada $(n=2)$, the Netherlands $(n=2)$, and Brazil $(n=2)$. In addition, there was one article from each of the following countries: Belgium, Turkey, Austria, Taiwan, and Greece. Table 2 displays and summarizes different components of QoL in PCOS women.

\section{Instruments used}

Various general and specific questionnaires were used to assess QoL in PCOS women. Overall, three specific and 5 general measures were used to assess the QoL in PCOS women. Of these, one general instrument (36-Item Short Form Health Survey [SF-36]) and one specific instrument (Polycystic Ovary Syndrome Health-Related Quality of Life Questionnaire [PCOSQ]) were used most frequently (Table 3). The generic questionnaires were the following: the SF-36 $(n=17)$, Symptom Checklist-90-Revised (SCL-90-R; n=5), World Health Organization Qualityof-Life-BREF (WHOQOL-BREF; n=4), Child Health Questionnaire-Child Form (CHQ-CF87; n=3), and General 


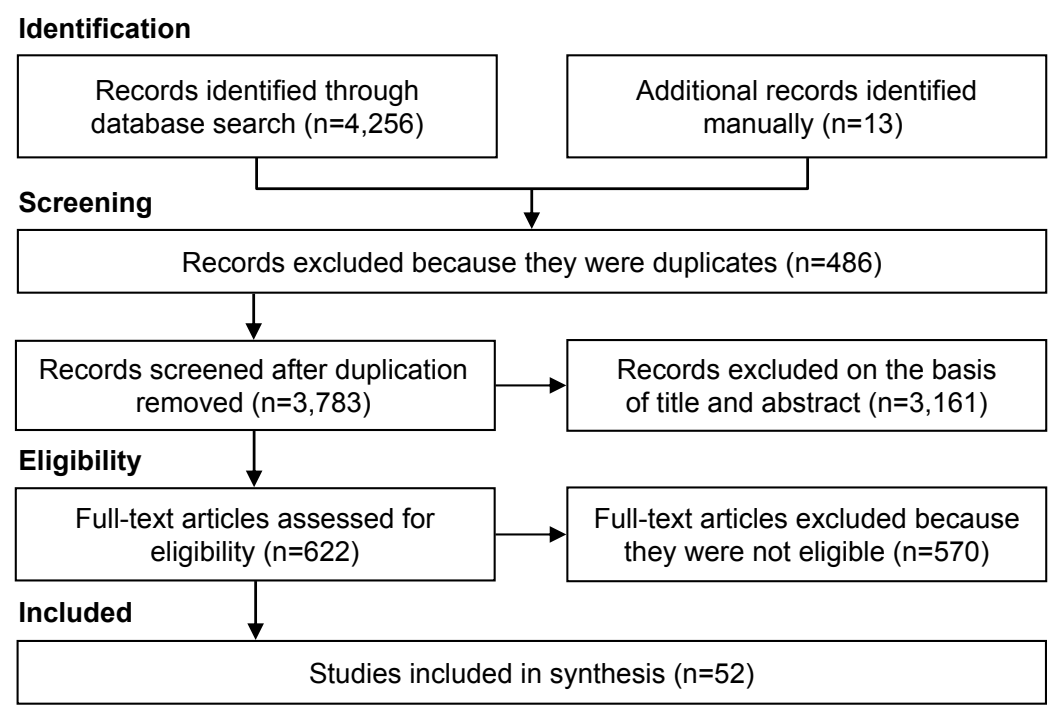

Figure I The flow diagram of the review.

Health Questionnaire-28 ( $\mathrm{n}=1)$. The PCOS disease-specific instruments were the PCOSQ $(n=20)$, the Modified PCOSQ (MPCOSQ; n=3), and the Polycystic Ovary Syndrome Questionnaire (PCOSQ-50; $\mathrm{n}=1$ ). In the following sections, a short description for each of these is presented.

\section{PCOSQ/MPCOSQ}

The PCOSQ is an instrument that was specifically designed and validated to evaluate HRQoL in PCOS. ${ }^{21-23}$ In the first stage of the instrument development, 182 items were incorporated which belonged to 8 areas chosen as a result of running semi-structured interviews with 10 patients suffering from PCOS and an extensive literature review. ${ }^{21}$ In item reduction phase, 100 women with PCOS completed the instrument, and they identified the items of highest impact on their daily lives. By considering the factors influencing women and identifying the items that clinicians take as important, a factor analysis was performed, and the final questionnaire containing 26 items was provided. The PCOSQ contains the following domains: emotions ( 8 items), hirsutism (5 items), weight ( 5 items), infertility (4 items), and menstrual disorders (4 items). Each item can be answered by choosing from a Likert scale with 7 options from 1 (always) to 7 (never). Higher scores are indicative of better function. Studies that incorporated the PCOSQ revealed that women with PCOS had functioning impairments pertinent to some measured domains. ${ }^{24-29}$ However, the relative degree of impairment caused by each domain varied in societies depending on the religious, racial, cultural, and social factors. ${ }^{24}$ Excess body weight has been widely reported as an important concern to women with PCOS, especially in adolescents. ${ }^{27,30-32}$ In two more studies that were carried out in Australia and Germany, body weight domain was found to have the strongest association with lower QoL. ${ }^{33,34}$ The psychometric properties of PCOSQ are well documented in several studies indicating that it is a reliable and valid measure for assessing QoL in PCOS women. 22,23,25,35 However, the PCOSQ was modified by Barnard et al, and 4 questions were added to it in order to evaluate issues associated with acne. ${ }^{33}$ Thus, the MPCOSQ includes 30 questions from $6 \mathrm{HRQoL}$ domains: emotional disturbance ( 8 items), weight concerns ( 5 items), infertility (4 items), acne (4 items), menstrual symptoms and predictability (4 items), and hirsutism ( 5 items). Each item was rated on a 7-point Likert scale where higher scores represent better function. The psychometric properties of the MPCOSQ were promising. ${ }^{33}$ Using this instrument, Bazarganipour et al in a cross-sectional study of 300 women with PCOS found that infertility and menstrual domains were the most affected areas of HRQoL. ${ }^{36}$

\section{PCOSQ-50}

The PCOSQ-50 was specifically developed by Nasiri-Amiri et al for measuring QoL in PCOS women. ${ }^{37}$ They used a mixed-method, sequential, exploratory design to define the components of health-related QoL questionnaire and assessed the psychometric properties of instrument. A rudimentary questionnaire composed of 147 items was designed drawing on the findings of a qualitative study that was carried out with 23 Iranian women who suffered from PCOS. Exploratory factor analysis helped to reduce the number of items from 


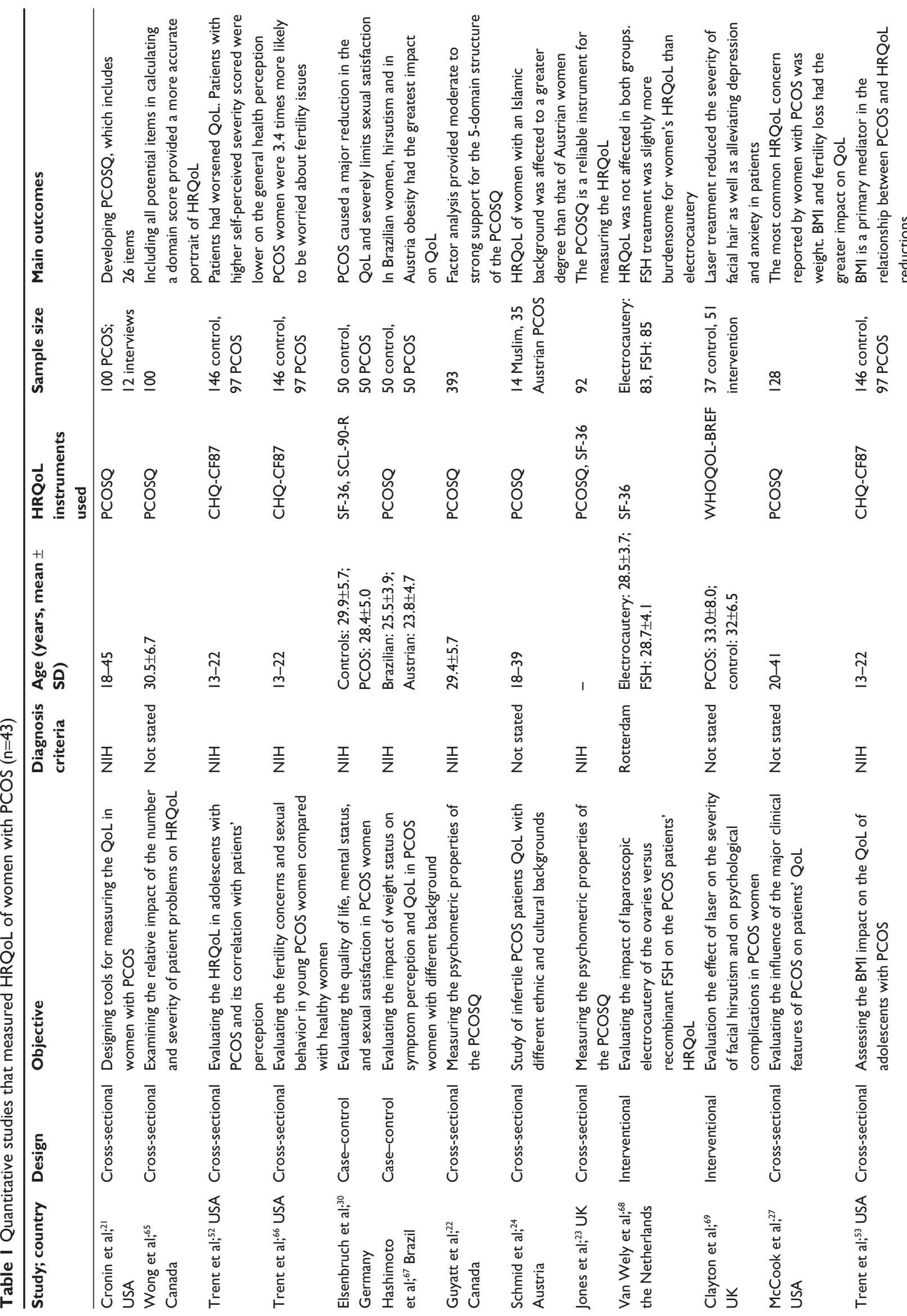




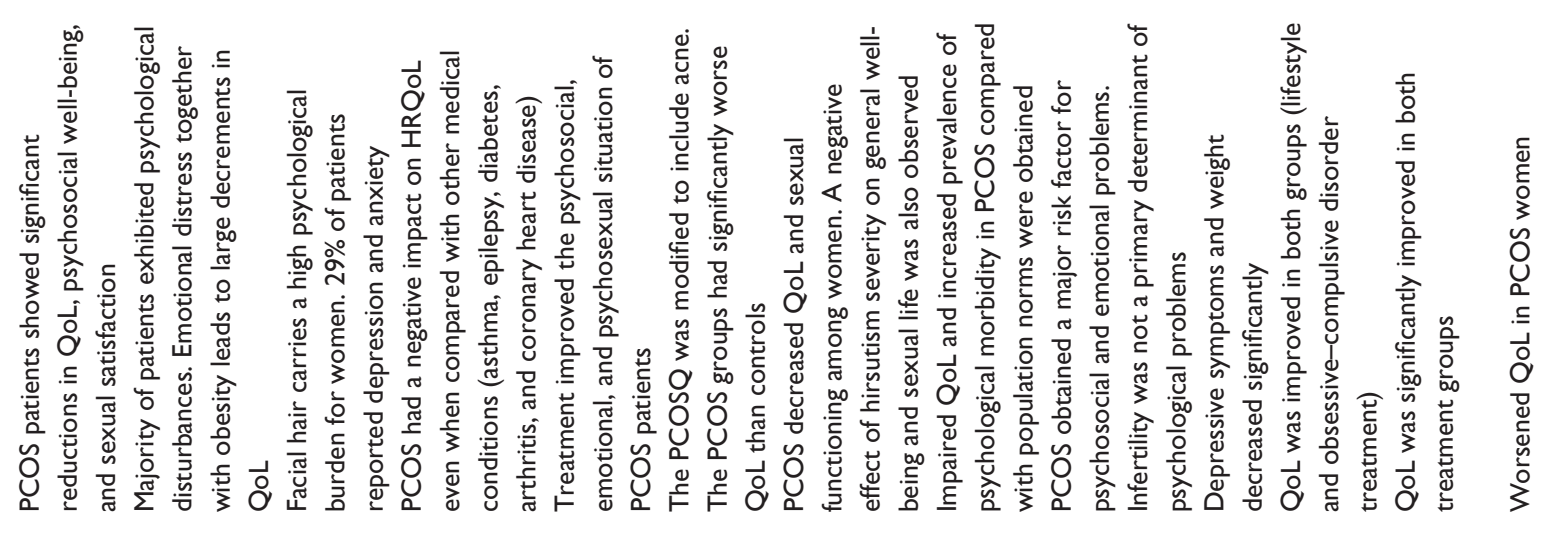

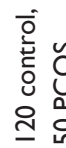<smiles>C1CCCCC1</smiles>

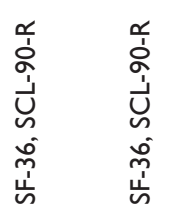

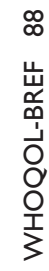

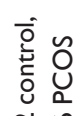

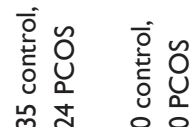

원

은

$\stackrel{\sim}{\sim} \stackrel{\infty}{\sim}$

to

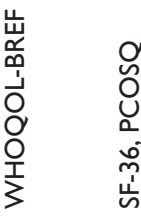

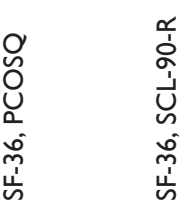

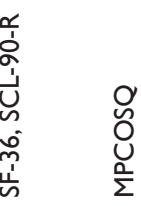

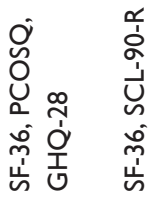

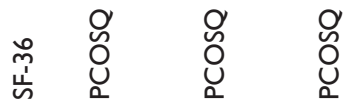

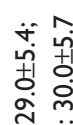

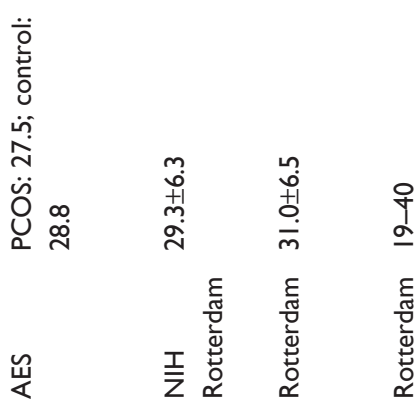

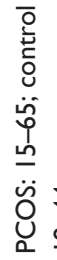

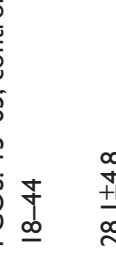

$\overline{\underline{I}} \quad \underline{\bar{z}}$

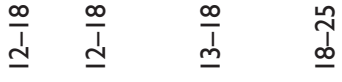

I I

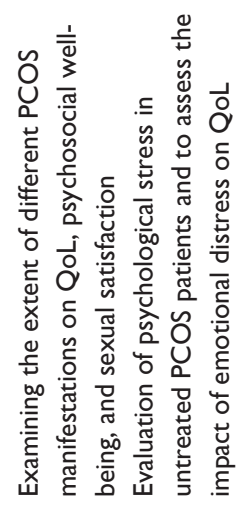

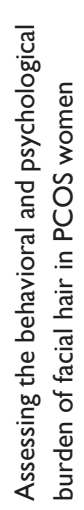

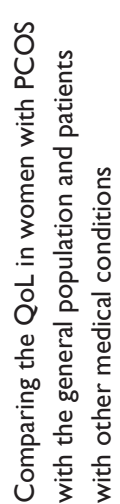

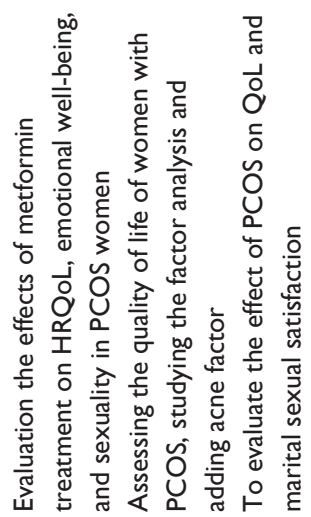

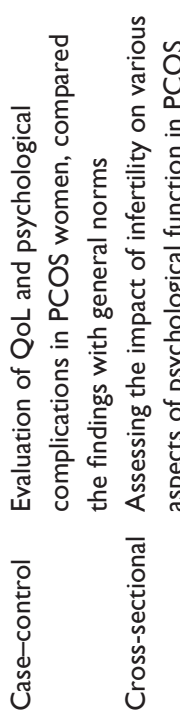

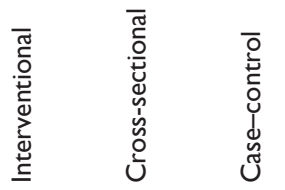

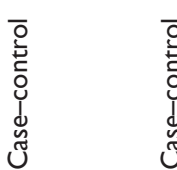

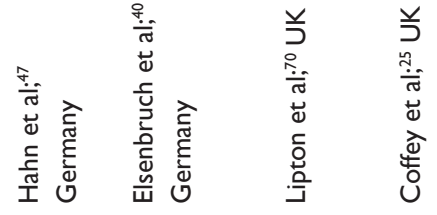

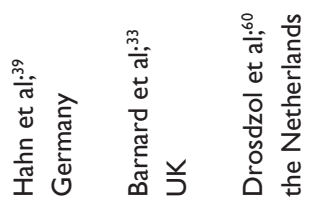

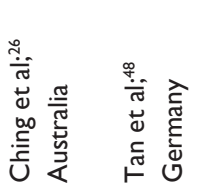

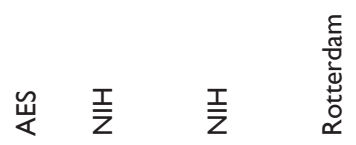

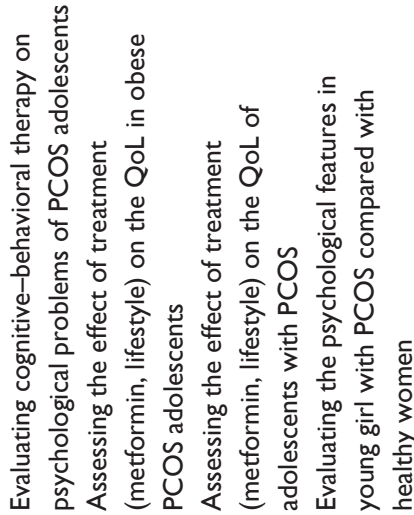

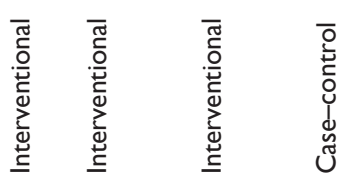

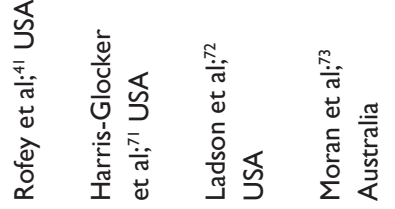




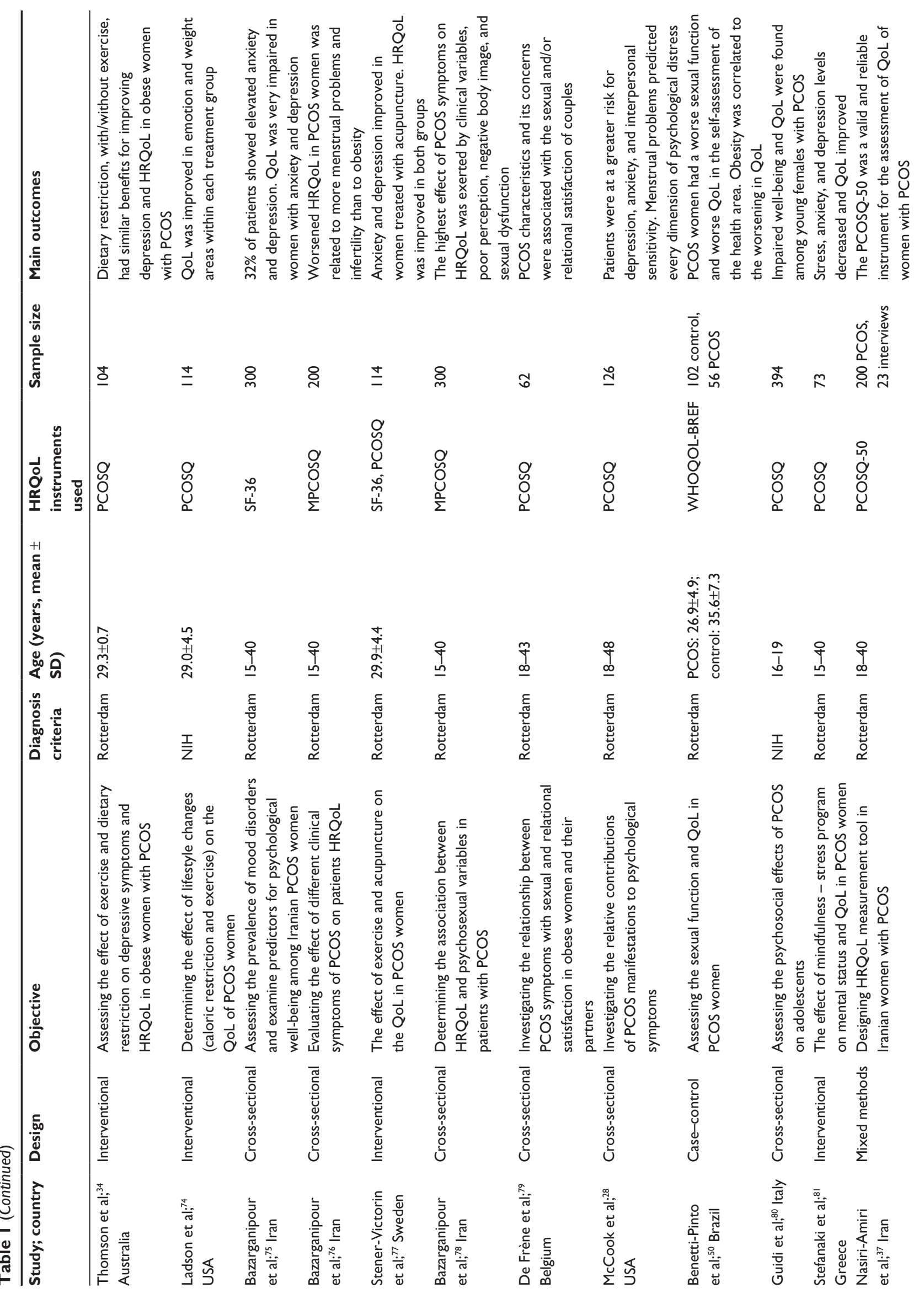




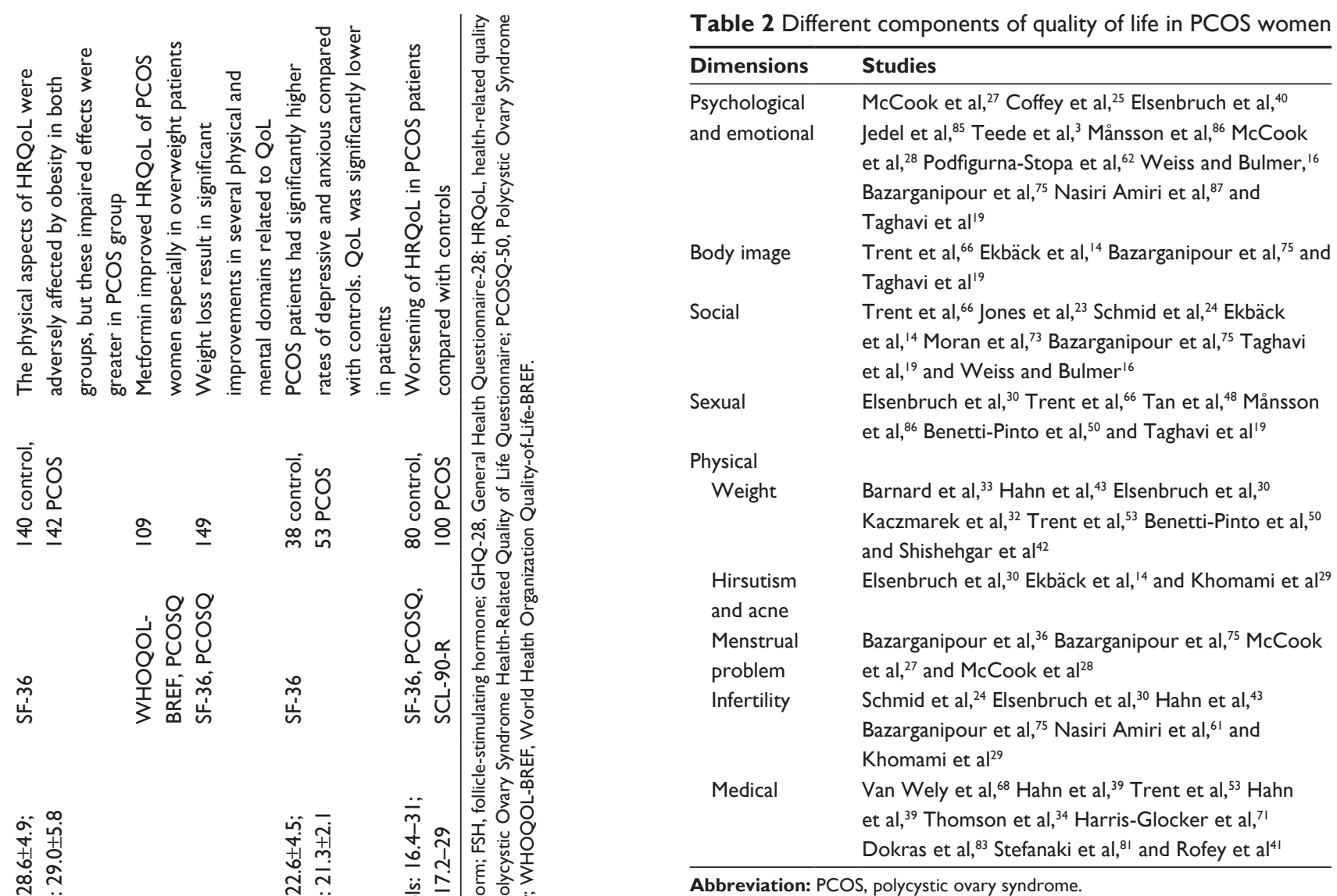

Abbreviation: PCOS, polycystic ovary syndrome.

147 to 50 . The ultimate draft of the questionnaire incorporated 50 items representing 6 areas, namely emotion, obesity and menstrual disorders, fertility, sexual function, hirsutism, and coping. Each item could be answered by selecting from options on a 5-point Likert scale with higher scores meaning better condition. The analysis of the psychometric properties of the questionnaire revealed promising results.

\section{SF-36}

The SF-36 is one of the most acknowledged and most frequently used instruments to measure QoL. The SF-36 is used in all types of patients and has been validated in many countries. This instrument has been proved to be reliable and widely validated and has been employed in the assessment of HRQoL in various medical conditions. It consists of 36 items tapping into 8 subscales, namely physical functioning, role physical, bodily pain, general health, vitality, social functioning, role emotional, and mental health. ${ }^{38}$ The scores on each domain range from 0 to 100 where the higher scores indicate better conditions. Several studies used the SF-36 in order to assess HRQoL in PCOS patients. ${ }^{30,39-42}$ Findings have been rather consistent in revealing lower HRQoL in women suffering from PCOS. However, evidence suggests 
Table 3 Most general and specific instruments for assessing HRQoL in women with PCOS

\begin{tabular}{|c|c|c|c|}
\hline Instruments & $\begin{array}{l}\text { No of } \\
\text { items }\end{array}$ & Dimensions covered & Studies \\
\hline \multicolumn{4}{|l|}{ General instruments } \\
\hline SF-36 & 36 & $\begin{array}{l}\text { Physical functioning, vitality/energy, physical role } \\
\text { limitation, bodily pain, mental health, emotional } \\
\text { role limitation, general health perception, and social } \\
\text { functioning }\end{array}$ & 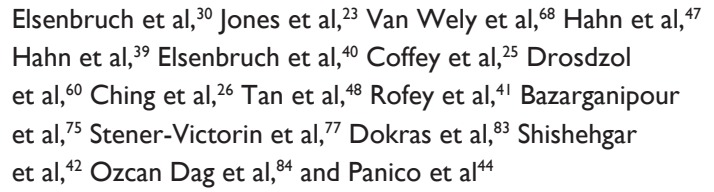 \\
\hline SCL-90-R & 90 & $\begin{array}{l}\text { Somatization, obsessive-compulsive, interpersonal } \\
\text { sensitivity, paranoid ideation, psychoticism, anxiety } \\
\text { depression, phobia, and aggression }\end{array}$ & $\begin{array}{l}\text { Elsenbruch et al, }{ }^{30} \text { Hahn et al, }{ }^{47} \text { Hahn et al, }{ }^{39} \text { Elsenbruch et al, }{ }^{40} \\
\text { and Tan et al }{ }^{48}\end{array}$ \\
\hline CHQ-CF87 & 87 & $\begin{array}{l}\text { Change in health in the last year, role/social } \\
\text { emotional, behavioral, physical, bodily pain, } \\
\text { behavior, mental health, self-esteem, general health } \\
\text { perceptions, family activities, family cohesion, and } \\
\text { physical functioning }\end{array}$ & Trent et al, ${ }^{52}$ Trent et al, ${ }^{66}$ and Trent et al ${ }^{53}$ \\
\hline WHOQOL-BREF & 26 & $\begin{array}{l}\text { General health, physical health, psychological, } \\
\text { health, Social relationship, and environmental }\end{array}$ & $\begin{array}{l}\text { Clayton et al },^{69} \text { Lipton et al, }{ }^{70} \text { Benetti-Pinto et al, }{ }^{50} \text { and } \\
\text { Huang-TzOu et al }{ }^{82}\end{array}$ \\
\hline GHQ-28 & 28 & $\begin{array}{l}\text { Somatic symptom, anxiety/insomnia, social } \\
\text { dysfunction, and depression }\end{array}$ & Ching et $\mathrm{a}^{26}$ \\
\hline \multicolumn{4}{|l|}{ Specific instruments } \\
\hline PCOSQ & 26 & $\begin{array}{l}\text { Emotion, hirsutism, infertility, weight, and menstrual } \\
\text { problem }\end{array}$ & $\begin{array}{l}\text { Cronin et al, }{ }^{21} \text { Wong et al, }{ }^{65} \text { Hashimoto et al },^{67} \text { Guyatt } \\
\text { et al, }{ }^{22} \text { Jones et al, }{ }^{23} \text { Schmid et al, }{ }^{24} \text { McCook et al, },{ }^{27} \text { Coffey } \\
\text { et al, }{ }^{25} \text { Ching et al, }{ }^{26} \text { Rofey et al, }{ }^{41} \text { Harris-Glocker et al, }{ }^{71} \\
\text { Moran et al, }{ }^{73} \text { Thomson et al, }{ }^{34} \text { Ladson et al, }{ }^{72} \text { Stener-Victorin } \\
\text { et al, },^{77} \text { De Frène et al, }{ }^{79} \text { Stefanaki et al },{ }^{81} \text { McCook et al, }{ }^{28} \\
\text { Dokras et al, }{ }^{83} \text { and Panico et al }{ }^{44}\end{array}$ \\
\hline MPCOSQ & 30 & $\begin{array}{l}\text { Emotion, hirsutism, infertility, weight, menstrual } \\
\text { problem, and acne }\end{array}$ & Barnard et al, ${ }^{33}$ Bazarganipour et al, ${ }^{36}$ and Bazarganipour et a $\mathrm{a}^{78}$ \\
\hline PCOSQ-50 & 50 & $\begin{array}{l}\text { Psychosocial and emotional, fertility, sexual, obesity, } \\
\text { and menstrual disorders, hirsutism, and coping }\end{array}$ & Nasiri-Amiri et $\mathrm{al}^{37}$ \\
\hline
\end{tabular}

Abbreviations: CHQ-CF87, Child Health Questionnaire-Child Form; GHQ-28, General Health Questionnaire-28; HRQoL, health-related quality of life; MPCOSQ, Modified PCOSQ; PCOS, polycystic ovary syndrome; PCOSQ, Polycystic Ovary Syndrome Health-Related Quality of Life Questionnaire; PCOSQ-50, Polycystic Ovary Syndrome Questionnaire; SCL-90-R, Symptom Checklist-90-Revised; SF-36, 36-Item Short Form Health Survey; WHOQOL-BREF, World Health Organization Quality-of-Life-BREF.

that poor QoL in these women might be due to obesity. In some studies, it has been shown that body mass index (BMI) was a predictor of physical functioning as measured by the SF-36. ${ }^{43,44}$ Furthermore, by using a multivariable regression model, Panico et al in a recent study indicated that BMI is a predictor of physical functioning score. ${ }^{44}$ Jones et al found that the role emotional was the poorest area of health, with mean scores of 50.4 on the SF-36 questionnaire, which had the greatest negative impact on HRQoL in women with PCOS. ${ }^{23}$ In a study by Coffey et al, the psychological dimension was more affected than the physical dimension as measured by the SF- $36 .{ }^{25}$ Bazarganipour et al found that PCOS affected all domains in the SF-36, and psychological domains were most affected by PCOS. ${ }^{45}$

\section{SCL-90-R}

The SCL-90 has also been widely used and extensively validated. It includes 90 items grouped into 10 main domains, namely somatization, obsessive-compulsive, interpersonal sensitivity, depression, anxiety, aggression, phobia, paranoid ideation, psychoticism, and sleep disorders. ${ }^{46}$ Three global areas are measured, including the Global Severity Index, Positive Symptom Distress Index, and Positive Symptom Total. For each item related to a single domain, a score ranging from 0 (not at all) to 4 (very much) can be selected. Higher scores represent less favorable conditions. ${ }^{44}$ Some studies targeting adult women suffering from PCOS have employed the SCL-90 to measure life quality..$^{30,40,44,47,48}$ By using this tool, Elsenbruch et al showed that emotional distress and obesity in PCOS women are associated with significant decrease in HRQoL. ${ }^{40}$

\section{WHOQOL-BREF}

WHOQOL-BREF instrument is comprised of 26 items, which measure broad domains consisting of physical health, psychological health, social relationships, and environment. The WHOQOL-BREF is a shorter version of the original instrument and can be used for assessing the QoL in different 
cultures and populations. In a study on 146 women having PCOS and 170 controls who were assessed by the WHOQOLBREF questionnaire, it was discovered that the hirsutism scores were a major predictor of psychological distress and showed correlation with the emotion domain. ${ }^{49}$ In BenettiPinto et al's study, the BMI was inversely correlated to the QoL in women suffering from PCOS, mainly with the physical, psychological, and environmental aspects of QoL. ${ }^{50}$

\section{CHQ-CF87}

The CHQ-CF87 is a self-report questionnaire that was developed and validated at the Health Institute of the New England Medical Center in Boston. ${ }^{51}$ It has been used to measure HRQoL in general populations of youth. It consists of 12 summated scales and is designed to measure both the physical and psychosocial HRQoL of adolescents. The items on the CHQ-CF87 are scored from 0 to 100 except for the change in health in the last year, and the items on family cohesion subscales are scored from 1 to 5 as single-item measures. A higher score on each subscale indicates better QoL in a specific area or health improvement in the last year.

Trent et al in their study used the CHQ-CF87 and revealed that HRQoL scores of adolescents suffering from PCOS were significantly lower in 4 areas of physical functioning, general health perceptions, behavior, and family activities as measured by the questionnaire. ${ }^{52}$ These authors also carried out another study in this area and evaluated the influence of BMI on QoL disturbances in adolescent patients. PCOS adolescents had higher BMI than those of the controls and a significantly lower HRQoL. Similarly, PCOS girls scored lower on the general health perceptions, physical functioning, family activities, and the general behavior subscales of CHQ-CF87.53

\section{Discussion}

The studies identified in this review have shown that PCOS is a major cause of psychological morbidity and has a negative impact on women's HRQoL. This feature has also been demonstrated in some qualitative studies. ${ }^{13,14,16,19}$ In all the studies reviewed, different aspects of the QoL in PCOS women were evaluated including physical, psychological, social, sexual as well as medical ones.

The impact of PCOS on the HRQoL may be more specifically seen in the perception of values and culture, ${ }^{24}$ therefore, the major contributing factors of reductions of life quality in PCOS were discovered to be different in a variety of population. However, physical aspects of QoL may be best predicted by obesity and hirsutism. ${ }^{29,49}$ Excess body weight has been widely reported as an important concern to women with PCOS, especially in adolescents..$^{27,30-32}$ Obesity is believed to be a primary source for poor HRQoL and contributes substantially to negative psychological symptoms in women with PCOS. ${ }^{54}$ The findings of an Italian study that was recently performed yielded a significant aggravation of HRQoL in PCOS patients with obesity compared with controls. $^{44}$

Hirsutism can be found in nearly $70 \%$ of women suffering from $\mathrm{PCOS},{ }^{2}$ and patients take it as one of the most annoying aspects of PCOS. ${ }^{29,55}$ Women suffering from PCOS who experience hirsutism have often complained that they feel "unfeminine." $12,30,56,57$

The comparison of psychological well-beings between women suffering from PCOS and control groups showed an increased risk for emotional distress in those with PCOS. ${ }^{6}$ Recent meta-analysis in PCOS women has yielded a raise in the prevalence of both depressive and anxiety symptoms in women suffering from PCOS in comparison with controls. ${ }^{58}$ Loss of femininity, body image concerns, and coping with these conditions may all contribute to poorer mental health outcomes. $^{59}$

Moreover, changes in body dimensions and physical beauty as well as imbalance of sexual hormones could lead to reduction in QoL and sexual performance. Psychological distress from long-term health risks, infertility, and changes in appearance (obesity, acne, and hirsutism) can influence sexual function among PCOS women. ${ }^{50,60}$ These women often complain that they feel less attractive and being less sexually satisfied in comparison with non-PCOS women. ${ }^{30}$

PCOS can also affect patients' QoL socially. Based on the results of qualitative studies, other factors that affected QoL were the reduction of interpersonal and social relationships. ${ }^{61,62}$ Accordingly, Ekbäck et al in their qualitative study showed that hirsutism causes severe psychological burden and negatively affected patients' HRQoL and social interactions. ${ }^{14} \mathrm{~A}$ few studies explored the impact of treatment on HRQoL. In 2009, Rofey et al showed that an enhanced cognitive behavioral therapy was practical and encouraging for adolescents suffering from PCOS. ${ }^{41}$

One of the major findings of the current research was the high frequency of application of specific and general instruments such as PCOSQ and SF-36. In our review, 24 studies had used specific tools for this purpose, and general questionnaires had been applied in other studies. PCOS affects women both psychologically and physically according to the SF-36. A recent meta-analysis showed that women with PCOS score lower in each dimension of the 
SF-36, mostly in the "Role Emotional" subscale. ${ }^{7}$ General tools are designed to measure HRQoL in a wide range of diseases and therefore may not be sensitive enough to be used in specific conditions. ${ }^{63}$ However, specific tools such as PCOSQ include some certain questions for these conditions. Obesity, hirsutism, irregular menses, and infertility are different aspects of PCOS exerting negative impacts on HRQoL that would not easily be detected by employing only a generic questionnaire. By using PCOSQ, it was demonstrated that clinical symptoms of PCOS, especially excess body weight ${ }^{22,23,25-27}$ and hirsutism, ${ }^{29}$ could compromise women's QoL. Ideally, employing both general and specific disease instruments in measuring HRQoL is recommended in order to make comparisons possible at a generic level and especially in the case of the disease under focus. ${ }^{64}$

\section{Conclusion}

PCOS symptoms can result in remarkable worsening of life quality and may be highly stressful, adversely affecting psychological, social well-being and sexuality. This study revealed that the specific questionnaire PCOSQ and the SF-36 were mainly used for measuring life quality in women having PCOS. Perhaps using either a specific questionnaire solely or a specific questionnaire in conjunction with a generic measure would be more appropriate when measuring QoL in PCOS women. However, both questionnaires showed that they are able to capture different aspects of QoL in PCOS women and to identify areas that can help to improve QoL in these women.

\section{Acknowledgments}

We would like to thank the Tehran University's vicechancellor of education and vice-chancellor of research and technology for their financial support to carry out the study. This article is a part of the $\mathrm{PhD}$ thesis of Bita Feridoni supported by Tehran University of Medical Sciences (the ethics code: IR.TUMS.FNM.REC.1395.781).

\section{Disclosure}

The authors report no conflicts of interest in this work.

\section{References}

1. Sirmans SM, Pate KA. Epidemiology, diagnosis, and management of polycystic ovary syndrome. Clin Epidemiol. 2013;6:1-13.

2. Fauser BC, Tarlatzis BC, Rebar RW, et al. Consensus on women's health aspects of polycystic ovary syndrome (PCOS): the Amsterdam ESHRE/ ASRM-Sponsored 3rd PCOS Consensus Workshop Group. Fertil Steril. 2012;97:28-38.

3. Teede H, Deeks A, Moran L. Polycystic ovary syndrome: a complex condition with psychological, reproductive and metabolic manifestations that impacts on health across the lifespan. BMC Med. 2010;8:41.
4. Rotterdam ESHRE/ASRM-Sponsored PCOS Consensus Workshop Group. Revised 2003 consensus on diagnostic criteria and long-term health risks related to polycystic ovary syndrome (PCOS). Hum Reprod. 2004; 19:41-47.

5. Moran LJ, Norman RJ, Teede HJ. Metabolic risk in PCOS: phenotype and adiposity impact. Trends Endocrinol Metab. 2015;26:136-143.

6. Veltman-Verhulst SM, Boivin J, Eijkemans MJ, Fauser BJ. Emotional distress is a common risk in women with polycystic ovary syndrome: a systematic review and meta-analysis of 28 studies. Hum Reprod Update. 2012;18:638-651.

7. Li Y, Li Y, Yu Ng EH, et al. Polycystic ovary syndrome is associated with negatively variable impacts on domains of health-related quality of life: evidence from a meta-analysis. Fertil Steril. 2011;96:452-458.

8. Colwell HH, Mathias SD, Pasta DJ, Henning JM, Steege JF. A healthrelated quality-of-life instrument for symptomatic patients with endometriosis: a validation study. Am J Obstet Gynecol. 1998;179:47-55.

9. Stracquadanio M, Ciotta L. Metabolic Aspects of PCOS: Treatment with Insulin Sensitizers. Switzerland: Springer International Publishing; 2015.

10. Luckett T, King M, Butow P, Friedlander M, Paris T. Assessing healthrelated quality of life in gynecologic oncology: a systematic review of questionnaires and their ability to detect clinically important differences and change. Int J Gynecol Cancer. 2010;20:664-684.

11. Terwee CB, Bot SD, de Boer MR, et al. Quality criteria were proposed for measurement properties of health status questionnaires. $J$ Clin Epidemiol. 2007;60:34-42.

12. Kitzinger C, Willmott J. 'The thief of womanhood': women's experience of polycystic ovarian syndrome. Soc Sci Med. 2002;54:349-361.

13. Snyder BS. The lived experience of women diagnosed with polycystic ovary syndrome. J Obstet Gynecol Neonatal Nurs. 2006;35:385-392.

14. Ekbäck M, Wijma K, Benzein E. "It is always on my mind": women's experiences of their bodies when living with hirsutism. Health Care Women Int. 2009;30:358-372.

15. Percy CA, Gibbs T, Potter L, Boardman S. Nurse-led peer support group: experiences of women with polycystic ovary syndrome. J Adv Nurs. 2009;65:2046-2055.

16. Weiss TR, Bulmer SM. Young women's experiences living with polycystic ovary syndrome. J Obstet Gynecol Neonatal Nurs. 2011;40: 709-718.

17. Jones GL, Hall JM, Lashen HL, Balen AH, Ledger WL. Health-related quality of life among adolescents with polycystic ovary syndrome. J Obstet Gynecol Neonatal Nurs. 2011;40:577-588.

18. Nasiri Amiri F, Ramezani Tehrani F, Simbar M, Mohammadpour Thamtan RA, Shiva N. Female gender scheme is disturbed by polycystic ovary syndrome: a qualitative study from Iran. Iran Red Crescent Med J. 2014;16:e12423.

19. Taghavi SA, Bazarganipour F, Hugh-Jones S, Hosseini N. Healthrelated quality of life in Iranian women with polycystic ovary syndrome: a qualitative study. BMC Womens Health. 2015;15:111.

20. Williams S, Sheffield D, Knibb RC. 'Everything's from the inside out with PCOS': exploring women's experiences of living with polycystic ovary syndrome and co-morbidities through Skype ${ }^{\mathrm{TM}}$ interviews. Health Psychol Open. 2015;2:2055102915603051.

21. Cronin L, Guyatt G, Griffith L, et al. Development of a health-related quality-of-life questionnaire (PCOSQ) for women with polycystic ovary syndrome (PCOS). J Clin Endocrinol Metab. 1998;83:1976-1987.

22. Guyatt G, Weaver B, Cronin L, Dooley JA, Azziz R. Health-related quality of life in women with polycystic ovary syndrome, a self-administered questionnaire, was validated. J Clin Epidemiol. 2004;57:1279-1287.

23. Jones G, Benes K, Clark TL, et al. The Polycystic Ovary Syndrome Health-Related Quality of Life Questionnaire (PCOSQ): a validation. Hum Reprod. 2004;19:371-377.

24. Schmid J, Kirchengast S, Vytiska-Binstorfer E, Huber J. Infertility caused by PCOS - health-related quality of life among Austrian and Moslem immigrant women in Austria. Hum Reprod. 2004;19:2251-2257.

25. Coffey S, Bano G, Mason HD. Health-related quality of life in women with polycystic ovary syndrome: a comparison with the general population using the Polycystic Ovary Syndrome Questionnaire (PCOSQ) and the Short Form-36 (SF-36). Gynecol Endocrinol. 2006;22:80-86. 
26. Ching HL, Burke V, Stuckey BG. Quality of life and psychological morbidity in women with polycystic ovary syndrome: body mass index, age and the provision of patient information are significant modifiers. Clin Endocrinol (Oxf). 2007;66:373-379.

27. McCook JG, Reame NE, Thatcher SS. Health-related quality of life issues in women with polycystic ovary syndrome. J Obstet Gynecol Neonatal Nurs. 2005;34:12-20.

28. McCook JG, Bailey BA, Williams SL, Anand S, Reame NE. Differential contributions of polycystic ovary syndrome (PCOS) manifestations to psychological symptoms. J Behav Health Serv Res. 2015;42: 383-394.

29. Khomami MB, Tehrani FR, Hashemi S, Farahmand M, Azizi F. Of PCOS symptoms, hirsutism has the most significant impact on the quality of life of Iranian women. PLoS One. 2015;10:e123608.

30. Elsenbruch S, Hahn S, Kowalsky D, et al. Quality of life, psychosocial well-being, and sexual satisfaction in women with polycystic ovary syndrome. J Clin Endocrinol Metab. 2003;88:5801-5807.

31. Kerchner A, Lester W, Stuart SP, Dokras A. Risk of depression and other mental health disorders in women with polycystic ovary syndrome a longitudinal study. Fertil Steril. 2009;91:207-212.

32. Kaczmarek C, Haller DM, Yaron M. Health related quality of life in adolescents and young adults with polycystic ovary syndrome: a systematic review. J Pediatr Adolesc Gynecol. 2016;29:551-557.

33. Barnard L, Ferriday D, Guenther N, Strauss B, Balen AH, Dye L. Quality of life and psychological well being in polycystic ovary syndrome. Hum Reprod. 2007;22:2279-2286.

34. Thomson RL, Buckley JD, Lim SS, et al. Lifestyle management improves quality of life and depression in overweight and obese women with polycystic ovary syndrome. Fertil Steril. 2010;94:1812-1816.

35. Malik-Aslam A, Reaney MD, Speight J. The suitability of polycystic ovary syndrome-specific questionnaires for measuring the impact of PCOS on quality of life in clinical trials. Value Health. 2010;13: 440-446.

36. Bazarganipour F, Ziaei S, Montazeri A, Foroozanfard F, Kazemnejad A, Faghihzadeh S. Predictive factors of health-related quality of life in patients with polycystic ovary syndrome: a structural equation modeling approach. Fertil Steril. 2013;100:1389-1396.

37. Nasiri-Amiri F, Ramezani Tehrani F, Simbar M, Montazeri A, Mohammadpour RA. Health-related quality of life questionnaire for polycystic ovary syndrome (PCOSQ-50): development and psychometric properties. Qual Life Res. 2016;25:1791-1801.

38. Shiely JC, Bayliss MS, Keller SD, et al. SF-36 Health Survey Annotated Bibliography. Boston: Health Institute, New England Medical Center; 1996.

39. Hahn S, Benson S, Elsenbruch S, et al. Metformin treatment of polycystic ovary syndrome improves health-related quality-of-life, emotional distress and sexuality. Hum Reprod. 2006;21:1925-1934.

40. Elsenbruch S, Benson S, Hahn S, et al. Determinants of emotional distress in women with polycystic ovary syndrome. Hum Reprod. 2006;21:1092-1099.

41. Rofey DL, Szigethy EM, Noll RB, Dahl RE, Lobst E, Arslanian SA. Cognitive-Behavioral therapy for physical and emotional disturbances in adolescents with polycystic ovary syndrome: a pilot study. J Pediatr Psychol. 2009;34:156-163.

42. Shishehgar F, Ramezani Tehrani F, Mirmiran P, Hajian S, Baghestani AR. Comparison of the association of excess weight on health related quality of life of women with polycystic ovary syndrome: an age-and BMImatched case control study. PLoS One. 2016;11:e0162911.

43. Hahn S, Tan S, Elsenbruch S, et al. Clinical and biochemical characterization of women with polycystic ovary syndrome in North RhineWestphalia. Horm Metab Res. 2005;37:438-444.

44. Panico A, Messina G, Lupoli GA, et al. Quality of life in overweight (obese) and normal-weight women with polycystic ovary syndrome Patient Prefer Adherence. 2017;11:423-429.

45. Bazarganipour F, Ziaei S, Montazeri A, Foroozanfard F, Faghihzadeh S. Iranian version of modified polycystic ovary syndrome health-related quality of life questionnaire: discriminant and convergent validity. Iran J Reprod Med. 2013;11:753-760.
46. Derogatis LR. SCL-90-R: Administration, Scoring and Procedures Manual for the R (evised) Version and Other Instruments of the Psychopathology Rating Scale Series. Towson, MD: Clinical Psychometric Research; 1992.

47. Hahn S, Janssen OE, Tan S, et al. Clinical and psychological correlates of quality-of-life in polycystic ovary syndrome. Eur $J$ Endocrinol. 2005; 153:853-860.

48. Tan S, Hahn S, Benson S, et al. Psychological implications of infertility in women with polycystic ovary syndrome. Hum Reprod. 2008;23: 2064-2071.

49. Kumarapeli V, Seneviratne Rde A, Wijeyaratne CN, Yapa RM, Dodampahala SH. A simple screening approach for assessing community prevalence and phenotype of polycystic ovary syndrome in a semiurban population in Sri Lanka. Am J Epidemiol. 2008;168:321-328.

50. Benetti-Pinto CL, Ferreira SR, Antunes A Jr, Yela DA. The influence of body weight on sexual function and quality of life in women with polycystic ovary syndrome. Arch Gynecol Obstet. 2015;291:451-455.

51. Landgraf J, Abetz L, Ware J. The CHQ User's Manual. Boston: The Health Institute, New England Medical Center; 1996:571.

52. Trent ME, Rich M, Austin SB, Gordon CM. Quality of life in adolescent girls with polycystic ovary syndrome. Arch Pediatr Adolesc Med. 2002; 156:556-560.

53. Trent M, Austin SB, Rich M, Gordon CM. Overweight status of adolescent girls with polycystic ovary syndrome: body mass index as mediator of quality of life. Ambul Pediatr. 2005;5:107-111.

54. Ching HL, Burke V, Stuckey BG. Quality of life and psychological morbidity in women with polycystic ovary syndrome: body mass index, age and the provision of patient information are significant modifiers. Clin Endocrinol (Oxf). 2007;66:373-379.

55. Keegan A, Liao LM, Boyle M. 'Hirsutism': a psychological analysis. J Health Psychol. 2003;8:327-345.

56. Drosdzol A, Skrzypulec V, Mazur B, Pawlińska-Chmara R. Quality of life and marital sexual satisfaction in women with polycystic ovary syndrome. Folia Histochem Cytobiol. 2007;45:S93-S97.

57. Thomas SA, Fan AW, Pastore Lm. A review of the impact of body image on quality of life in women with polycystic ovary syndrome. Int J Psychol Res. 2014;9:17.

58. Cooney LG, Lee I, Sammel MD, Dokras A. High prevalence of moderate and severe depressive and anxiety symptoms in polycystic ovary syndrome: a systematic review and meta-analysis. Hum Reprod. 2017;32:1075-1091.

59. Deeks AA, Gibson-Helm ME, Paul E, Teede HJ. Is having polycystic ovary syndrome a predictor of poor psychological function including anxiety and depression? Hum Reprod. 2011;26:1399-1407.

60. Drosdzol A, Skrzypulec V, Mazur B, Pawlinska-Chmara R. Quality of life and marital sexual satisfaction in women with polycystic ovary syndrome. Folia Histochem Cytobiol. 2007;45:S93-S97.

61. Nasiri Amiri F, Ramezani Tehrani F, Simbar M, Montazeri A, Mohammadpour Thamtan RA. The experience of women affected by polycystic ovary syndrome: a qualitative study from Iran. Int $J$ Endocrinol Metab. 2014;12:e13612.

62. Podfigurna-Stopa A, Luisi S, Regini C, et al. Mood disorders and quality of life in polycystic ovary syndrome. Gynecol Endocrinol. 2015;31: $431-434$.

63. Jenkinson C. Assessment and Evaluation of Health and Medical Care: A Methods Text. UK: Open University Press; 1997.

64. Jones GL, Kennedy SH, Jenkinson C. Health-related quality of life measurement in women with common benign gynecologic conditions: a systematic review. Am J Obstet Gynecol. 2002;187:501-511.

65. Wong E, Cronin L, Griffith L, Irvine EJ, Guyatt GH. Problems of HRQL assessment: how much is too much? J Clin Epidemiol. 2001;54: 1081-1085.

66. Trent ME, Rich M, Austin SB, Gordon CM. Fertility concerns and sexual behavior in adolescent girls with polycystic ovary syndrome: implications for quality of life. J Pediatr Adolesc Gynecol. 2003;16:33-37.

67. Hashimoto DM, Schmid J, Martins FM, et al. The impact of the weight status on subjective symptomatology of the polycystic ovary syndrome: a cross-cultural comparison between Brazilian and Austrian women. Anthropol Anz. 2003;61:297-310. 
68. Van Wely M, Bayram N, Bossuyt PM, van der Veen F. Laparoscopic electrocautery of the ovaries versus recombinant FSH in clomiphene citrate-resistant polycystic ovary syndrome. Impact on women's healthrelated quality of life. Hum Reprod. 2004;19:2244-2250.

69. Clayton WJ, Lipton M, Elford J, Rustin M, Sherr L. A randomized controlled trial of laser treatment among hirsute women with polycystic ovary syndrome. Br J Dermatol. 2005;152:986-992.

70. Lipton MG, Sherr L, Elford J, Rustin MH, Clayton WJ. Women living with facial hair: the psychological and behavioral burden. J Psychosom Res. 2006;61:161-168.

71. Harris-Glocker M, Davidson K, Kochman L, Guzick D, Hoeger K. Improvement in quality-of-life questionnaire measures in obese adolescent females with polycystic ovary syndrome treated with lifestyle changes and oral contraceptives, with or without metformin. Fertil Steril. 2010;93:1016-1019.

72. Ladson G, Dodson WC, Sweet SD, et al. Effects of metformin in adolescents with polycystic ovary syndrome undertaking lifestyle therapy: a pilot randomized double-blind study. Fertil Steril. 2011;95:2595-2598. e1-e6.

73. Moran L, Gibson-Helm M, Teede H, Deeks A. Polycystic ovary syndrome: a biopsychosocial understanding in young women to improve knowledge and treatment options. J Psychosom Obstet Gynecol. 2010;31:24-31.

74. Ladson G, Dodson WC, Sweet SD, et al. The effects of metformin with lifestyle therapy in polycystic ovary syndrome: a randomized doubleblind study. Fertil Steril. 2011;95:1059-1066.e1-e7.

75. Bazarganipour F, Ziaei S, Montazeri A, Foroozanfard F, Kazemnejad A, Faghihzadeh S. Psychological investigation in patients with polycystic ovary syndrome. Health Qual Life Outcomes. 2013;11:141.

76. Bazarganipour F, Ziaei S, Montazeri A, Foroozanfard F, Faghihzadeh S. Health-related quality of life and its relationship with clinical symptoms among Iranian patients with polycystic ovarian syndrome. Iran J Reprod Med. 2013;11:371-378.

77. Stener-Victorin E, Holm G, Janson PO, Gustafson D, Waern M. Acupuncture and physical exercise for affective symptoms and healthrelated quality of life in polycystic ovary syndrome: secondary analysis from a randomized controlled trial. BMC Complement Altern Med. 2013; $13: 131$.
78. Bazarganipour F, Ziaei S, Montazeri A, Foroozanfard F, Kazemnejad A, Faghihzadeh S. Health-related quality of life in patients with polycystic ovary syndrome (PCOS): a model-based study of predictive factors. J Sex Med. 2014;11:1023-1032.

79. De Frène V, Verhofstadt L, Loeys T, Stuyver I, Buysse A, De Sutter P. Sexual and relational satisfaction in couples where the woman has polycystic ovary syndrome: a dyadic analysis. Hum Reprod. 2015;30: 625-631.

80. Guidi J, Gambineri A, Zanotti L, Fanelli F, Fava GA, Pasquali R. Psychological aspects of hyperandrogenic states in late adolescent and young women. Clin Endocrinol. 2015;83:872-878.

81. Stefanaki C, Bacopoulou F, Livadas S, et al. Impact of a mindfulness stress management program on stress, anxiety, depression and quality of life in women with polycystic ovary syndrome: a randomized controlled trial. Stress. 2015;18:57-66.

82. Huang-TzOu HT, Chen PC, Wu MH, Lin CY. Metformin improved health-related quality of life in ethnic Chinese women with polycystic ovary syndrome. Health Qual Life Outcomes. 2016;14:119.

83. Dokras A, Sarwer DB, Allison KC, et al. Weight loss and lowering androgens predict improvements in health related quality of life in women with PCOS. J Clin Endocrinol Metab. 2016;101(8):2966-2974.

84. Ozcan Dag Z, Alpua M, Isik Y, Buturak SV, Tulmac OB, Turkel Y. The evaluation of temperament and quality of life in patients with polycystic ovary syndrome. Gynecol Endocrinol. 2017;33:250-253.

85. Jedel E, Waern M, Gustafson D, et al. Anxiety and depression symptoms in women with polycystic ovary syndrome compared with controls matched for body mass index. Hum Reprod. 2010;25:450-456.

86. Månsson M, Norström K, Holte J, Landin-Wilhelmsen K, Dahlgren E, Landén M. Sexuality and psychological wellbeing in women with polycystic ovary syndrome compared with healthy controls. Eur J Obstet Gynecol Reprod Biol. 2011;155:161-165.

87. Nasiri Amiri F, Ramezani Tehrani F, Simbar M, Montazeri A, Mohammadpour Thamtan RA. The experience of women affected by polycystic ovary syndrome: a qualitative study from Iran. Int $J$ Endocrinol Metab. 2014;12:e13612.
International Journal of Women's Health

\section{Publish your work in this journal}

The International Journal of Women's Health is an international, peerreviewed open-access journal publishing original research, reports, editorials, reviews and commentaries on all aspects of women's healthcare including gynecology, obstetrics, and breast cancer. The manuscript management system is completely online and includes

\section{Dovepress}

a very quick and fair peer-review system, which is all easy to use Visit http://www.dovepress.com/testimonials.php to read real quotes from published authors. 